\title{
SAGITTAL DIAMETER OF FORAMEN MAGNUM IN NORMAL POPULATION: AN MRI STUDY
}

\author{
A. S. Lakshmi ${ }^{1}$ \\ ${ }^{1}$ Additional Professor, Department of Anatomy, Medical College, Trichur, Kerala.
}

\section{ABSTRACT}

\section{BACKGROUND}

Lower position of cerebellar tonsils was frequently noticed in Western studies. In some of the studies, sagittal diameter of foramen magnum was found to be larger in cases of Chiari malformation. However, there are no Indian studies for comparison. Our study was proposed to determine the standard values for sagittal diameter of foramen magnum in various age groups and both sexes. This gives a guideline for further studies in pathological conditions like Craniovertebral Junctional (CVJ) anomalies, and Chiari malformation. The sagittal diameter of foramen magnum was measured in 515 patients during MRI investigation directly on the MR images on the MR monitor in mid sagittal sections of head and cervical spine. The patients underwent the MR investigation for various vague complaints at the Radiology Department of SCTIMST, Trivandrum. They were found to have normal brain and spinal cord. They ranged from 2 months to 80 years of age in both sexes. Established cases of CVJ anomalies and raised intracranial tension were excluded. The results showed a mean sagittal diameter of $35.57 \pm 3.72 \mathrm{~mm}$ with a range of 15 to $45 \mathrm{~mm}$. The sagittal diameter increased up to 15 years, then remained static thereafter. Females showed smaller diameter compared to males. ANOVA showed a high statistically significant P-value of 0.001 for males and 0.004 for females. The study resulted in standard values of sagittal diameter of foramen magnum for different age groups in both sexes.

\section{KEYWORDS}

Foramen Magnum.

HOW TO CITE THIS ARTICLE: A. S. Lakshmi. "Sagittal Diameter of Foramen Magnum in Normal Population: An MRI Study." Journal of Evolution of Medical and Dental Sciences 2015; Vol. 4, Issue 95, November 26; Page: 16045-16047, DOI: $10.14260 /$ jemds/2015/2342.

\section{INTRODUCTION}

Chiari malformation is a congenital anomaly resulting in various grades of hind brain herniation through foramen magnum. It is frequently noticed in Kerala. In some of the Western studies. ${ }^{1}$ the sagittal diameter of foramen magnum was larger in established cases of Chiari malformation. However, there are no standard values available to compare the sagittal diameter between different age groups in normal population. Some of the studies have demonstrated sexual dimorphism in direct skull measurements. ${ }^{2,3}$ Our study aims at obtaining a standard reference value for sagittal diameter based on age and sex. This will establish guidelines for neuroradiologists for comparison in pathological studies like hind brain herniation.

\section{MATERIALS AND METHODS}

This study was conducted on 515 patients during MRI investigation at the Radiology Department of Sree Chithra Tirunal Institute of Medical Science and Technology (SCTIMST) in Trivandrum, Kerala, over a period of 7 months.

The subjects were chosen from a group of patients who underwent MRI scan for various vague complaints like headache, body ache, weakness etc. After MRI, patients with normal brain and spinal cord with normal Cranio-Vertebral Junction (CVJ) were selected.

Financial or Other, Competing Interest: None.

Submission 01-11-2015, Peer Review 02-11-2015,

Acceptance 11-11-2015, Published 25-11-2015.

Corresponding Author:

Dr. A. S. Lakshmi,

Additional Professor,

Department of Anatomy,

Medical College, Trichur-680596, Kerala.

E-mail: lakshmipadmanabhanblr@gmail.com DOI:10.14260/jemds/2015/2342.
The patients ranged from 2 months of age to 80 years in both sexes. Patients with raised intracranial tension and established CVJ anomalies were excluded. The equipment consisted of a super conducting magnet of 1.5 Tesla, manufactured by General Electric, USA.

Personal data of the patients was recorded. During the MRI scan, the brain, spinal cord, and CVJ region were thoroughly examined to rule out pathology. The sagittal diameter of foramen magnum was measured directly in the mid sagittal MRI image obtained on the monitor during the scan. The measurements were automatically recorded by controls on the operator's console. Basion and Ophisthion were marked ' $\mathrm{A}$ ' and ' $\mathrm{B}$ ' respectively (Figure 1). The sagittal diameter of the foramen magnum was equal to the distance between ' $\mathrm{A}$ ' and ' $\mathrm{B}$ '. The bones were easily identified by their low signal intensity. The data was analysed using the computer package SPSS/PC.

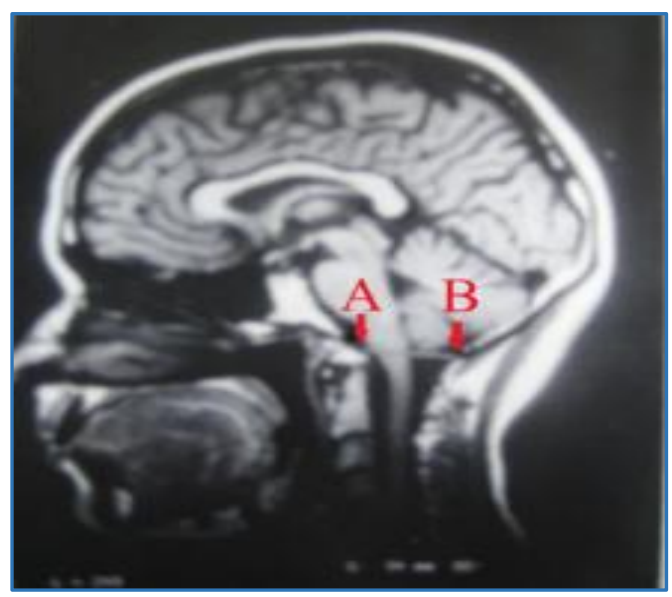

Fig.1: Sagittal Diameter Measurement of Foramen Magnum in MRI. 
RESULTS: The mean value of sagittal diameter of foramen magnum was $35.57 \pm 3.72 \mathrm{~mm}$ with a range of 15 to $45 \mathrm{~mm}$ (Table 1). The sagittal diameter of foramen magnum increased up to the age of 14, after which it remained unchanged. Hence, the age groups after the age of 15 years were combined and shown in our results. Table 1 shows the groups based on different stages in life, viz., infancy, early childhood, late childhood, and adolescents/adults.

The diameter of the foramen magnum was less in females compared to males. The mean values for the different age groups in both sexes are shown in Table 1 and Figure 2 . ANOVA showed a statistically high significant P-value of 0.001 for males and 0.004 for females.

\begin{tabular}{|c|c|c|}
\hline Age Group & Male & Female \\
\hline$<1$ year & $24.00 \pm 6.04(5)$ & $22.00 \pm 0.00(1)$ \\
\hline $1-4$ years & $33.73 \pm 3.80(11)$ & $34.00 \pm 4.36(5)$ \\
\hline 5 - 14 years & $35.00 \pm 2.83(31)$ & $33.68 \pm 3.86(25)$ \\
\hline $\begin{array}{c}\text { 15 years and } \\
\text { above }\end{array}$ & $\begin{array}{c}36.52 \pm 3.25 \\
(273)\end{array}$ & $34.87 \pm 3.04(164)$ \\
\hline P-value ANOVA & $<\mathbf{0 . 0 0 1}$ & $=\mathbf{0 . 0 0 4}$ \\
\hline \multicolumn{2}{|c|}{ Table 1: Sagittal Diameter of Foramen Magnum (In } \\
millimeters) by Age and Sex.
\end{tabular}

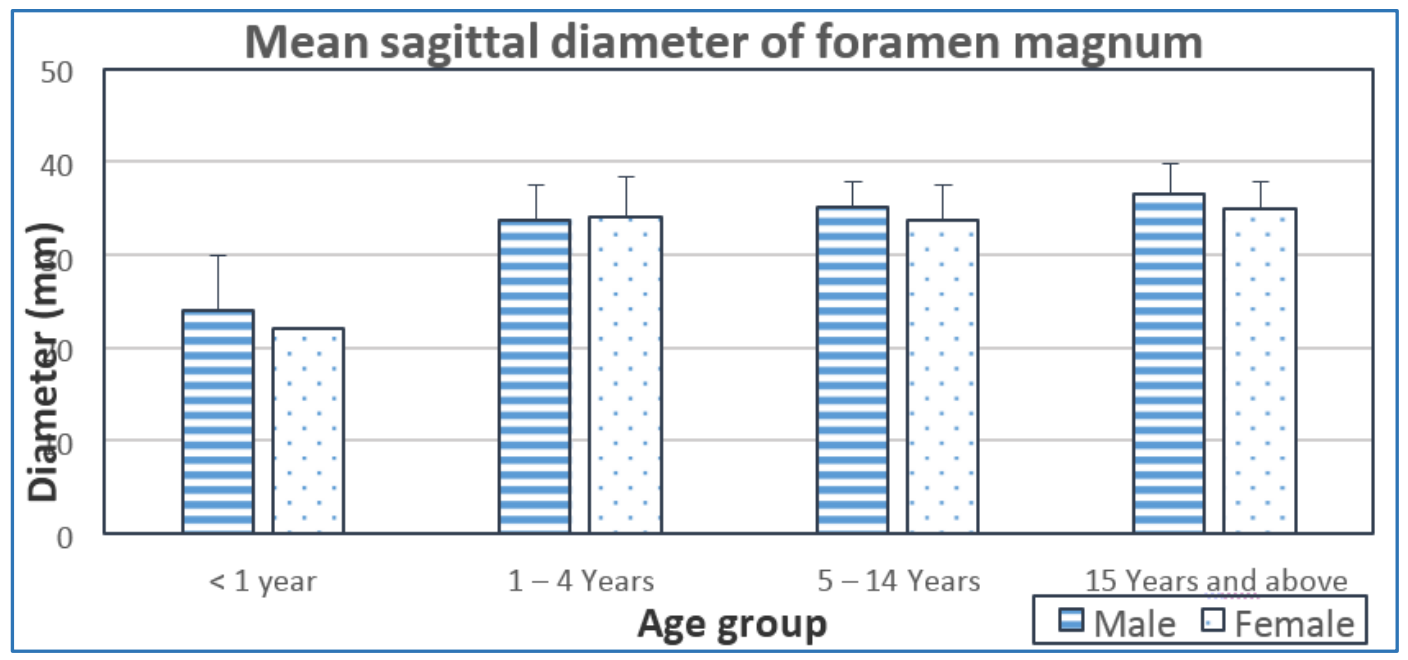

Fig. 2: Mean Sagittal Diameter of Foramen Magnum Classified by Age and Sex.

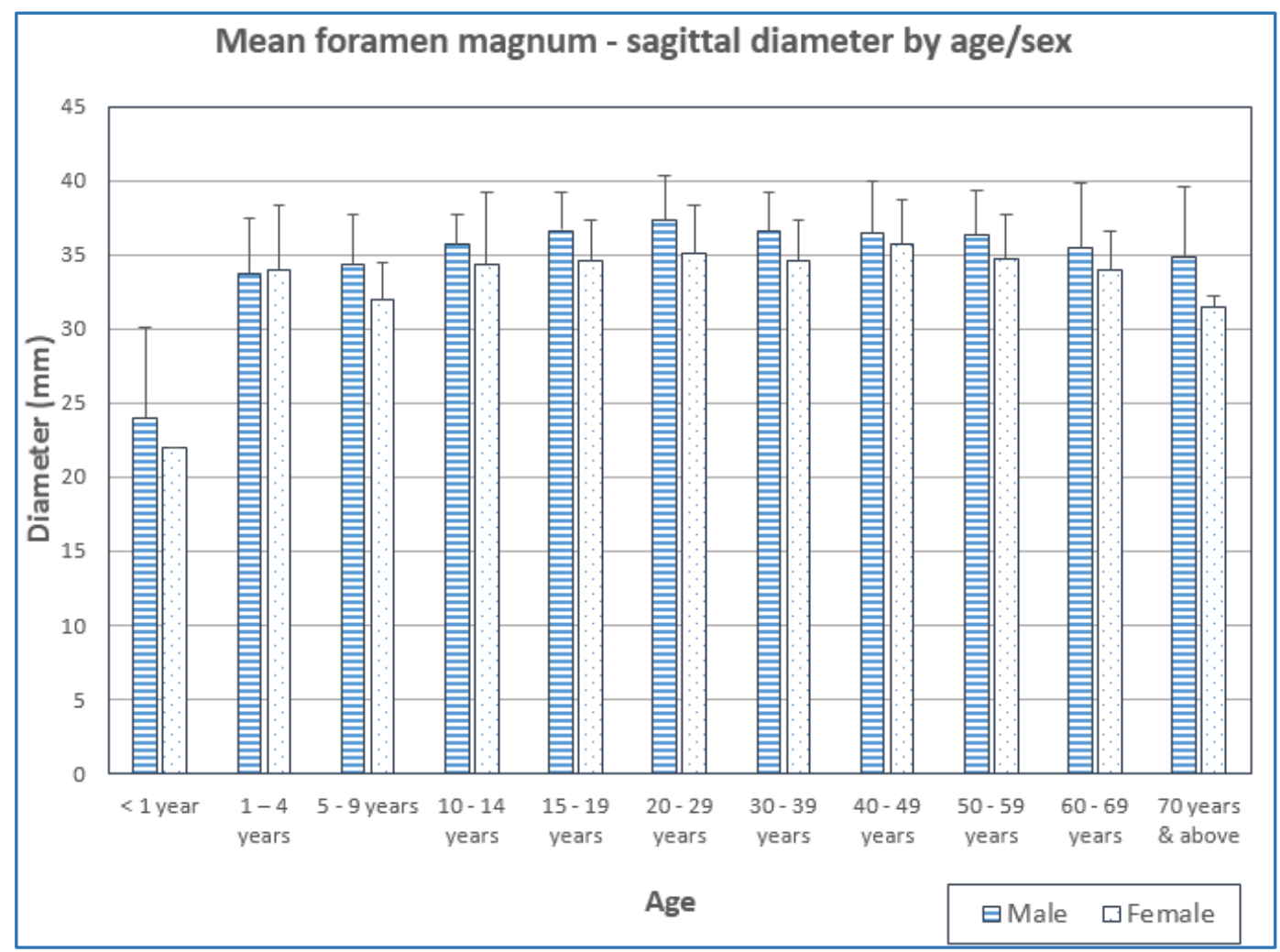

Fig. 3: Mean Foramen Magnum-Sagittal Diameter by Age/Sex 


\section{DISCUSSION}

According to standard textbooks of Anatomy. ${ }^{4}$ the sagittal diameter of foramen magnum is 3 to $4 \mathrm{~cm}$. A Western MRI study by Aboulezz. ${ }^{1}$ showed a mean value of $36.8 \pm 3.1 \mathrm{~mm}$ in 82 healthy subjects. The values of our study are in line with the study by Aboulezz.

A study by Shepur et al. ${ }^{2}$ showed larger foramen magnum in males compared to females by both osteometric and CT image study. The values were $33.4 \mathrm{~mm}$ for males and $33.1 \mathrm{~mm}$ for females. The CT image study by the same author showed $38.5 \mathrm{~mm}$ for males and $35.2 \mathrm{~mm}$ in females. However, no mention is made of age differences.

A study by Kamath et al. ${ }^{5}$ also shows sexual dimorphism in the sagittal diameter with males having larger foramen magnum. Several other authors (e.g. Olivier., ${ }^{6}$ Routal et al., ${ }^{7}$ Sayee et al.,8 Gruber et al., ${ }^{9}$ and Raghavendra Babu et al.10) have also shown similar results with a larger sagittal diameter of the foramen magnum in males. However, these studies do not depict any age differences as they have all used adult skulls.

In our study, the values for sagittal diameter are in consensus with the above mentioned studies with males showing a significantly larger foramen magnum. A very important finding was that the size of the sagittal diameter increased up to the second decade and remained constant thereafter in both sexes.

\section{CONCLUSION}

Our results indicate that a larger foramen magnum in the male could be due to growth differences because of hormonal influences and genetic factors.

The increase in size of the sagittal diameter up to the second decade could be due to the growth changes in the brain, spinal cord and soft tissues. The growing brain and spinal cord influences the increase in the skull cavity and forms a larger foramen by the resorption of the bone. The larger foramen accommodates the growing hind brain.

In the second decade when the growth stopped, the sagittal diameter of the foramen magnum might have attained the maximum size. The results can be used as a standard reference value for different ages and used for comparison in future pathological studies. Very large foramen in the younger age group may indicate development of Chiari malformation in late adulthood. This can be a scope for future studies.

\section{REFERENCES:}

1. Aboulezz A. O. et al. "Position of cerebellar tonsils in the normal population and in patients with Chiari malformation. A Quantitative approach with MR Imaging," J. Comp. Asst. Tomography 1985;9:pp10331036.

2. Muralidhar P, Shepur et al. "Morphometric Analysis of Foramen Magnum," Int J Anat Res 2014; Vol 2(1):pp24955.

3. AT Uthman et al. "Evaluation of foramen magnum in gender determination using helical CT scanning," Dentomaxillofacial Radiology 2012;41:pp197-202.

4. Williams et al. Gray's Anatomy 1995, 38th edition, Churchill Livingston.

5. Venkatesh Gokuldas Kamath et al. "Binary Logistic Regression Analysis of Foramen Magnum Dimensions for Sex Determination," Anatomy Research International Volume 2015; Article ID 459428: 9 pages.

6. G. Olivier. "Biometry of the human occipital bone." Journal of Anatomy 1975; Vol. 120, no. 3:pp507-518.

7. R. R. Routal et al. "Metrical studies with sexual dimorphism in foramen magnum of human crania." Journal of the Anatomical Society of India 1984; Vol. 33:pp85-89.

8. R. Sayee et al. "Foramen magnum measurements of Crania from Karnataka." Journal of the Anatomical Society of India 1987;Vol. 36:pp87-89.

9. P. Gruber et al. "Variability of human foramen magnum size." Anatomical Record 2009; Vol. 292, no. 11: pp 1713-1719.

10. Y. P. Raghavendra Babu et al. "Sex estimation from foramen magnum dimensions in an Indian population." Journal of Forensic and Legal Medicine 2012;Vol. 19, no. 3:pp162-167. 